\title{
Contemporary Documentary Film and "Archive Fever": History, the Fragment, the Joke
}

But if Derrida's Mal d'archive [Archive Fever] provokes that more serious thing, which is a joke, it is because the shade of the history writing that haunts its pages is — really — no laughing matter. In this light, then, if there is laughter, it will be some kind of homage, or at very least, a recognition, of what it is that has been revealed.

-Carolyn Steedman, Dust:The Archive and Cultural History

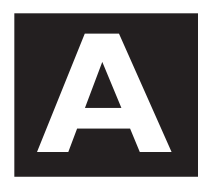

dele Horne's documentary The Tailenders (2005) begins with an image of a flat, square piece of cardboard labeled "Cardtalk." A hand reaches into the frame, unfolds the cardboard to form a box equipped with a tiny record needle, places a phonograph record beneath the needle, and then uses a pen inserted into a hole in the record to spin the disc. What emerges is a man's voice speaking in English and reciting a simple, didactic lesson that answers the question, "What is a Christian?" His voice is slightly distorted by the fact that the record is cranked by hand, but it is nonetheless intelligible.

The Tailenders' odd inaugural object sets up an enigma, one not so much resolved by the film as used as an entry point into complex issues of archivization, information dissemination, and power. Over subsequent black-andwhite archival images of people standing near similar hand-cranked phonographs, a woman's voice, Horne's, tells the story of Gospel Recordings, an evangelical missionary group founded in 1939 with the intention of recording Bible stories in every existing language and dialect in order, they say, to spread the same Christian message, translated but unchanged, across the world. The film then cuts to interviews with contemporary Gospel Recordings missionaries explaining their project and showing off their archive, which, they boast, contains recordings of more languages than any other archive in the world. The Cardtalk record in the first shot turns out to be a fragment from this vast collection.
Documentary film has long been enmeshed in a complex relationship with archives and archival practices. While many documentary filmmakers have drawn on archival materials - whether film footage, photographs, or other artifacts, like The Tailenders' recordings-as illustration or evidence, others have radically eschewed archives and relied only on their own footage. This split has at times been quite pronounced, especially in cases in which different modes of documentary practice are used to address the same historical subject.Alain Resnais'short documentary Night and Fog (1955), which makes use of shocking archival photographs of Auschwitz taken during the Holocaust, is often contrasted with Claude Lanzmann's nine-hour epic Shoah (1985), which relies only on footage shot by Lanzmann himself over a period of eleven years (Bruzzi 105). Certain found footage documentaries, like Emile de Antonio's “collage junk films” (24-25), contain nothing but skillfully edited archival footage, while orthodox direct cinema filmmakers insist on "being there," using

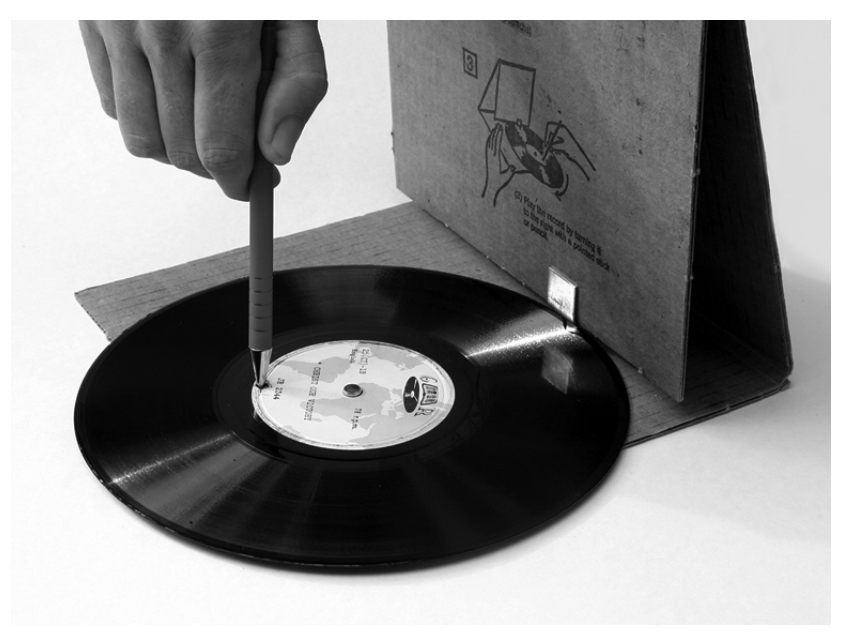

Figure I. The missionary group Gospel Recordings' hand-cranked "Cardtalk" record player in The Tailenders (Adele Horne, 2005) (photo by Karin Johansson). 
only material that they can capture through observing and recording their subjects firsthand. For the most part, however, documentary filmmakers rely on a combination of archival materials and their own contemporary footage, creating heterogeneous texts that oscillate in their relationship to present and past, made and found.

In the past few years, however, a number of independent documentaries have entered into a new relationship with archives and archival practices. Rather than simply mobilizing archival materials in a transparent manner, the four films I wish to discuss-The Tailenders (Adele Horne, 2005), The Birdpeople (Michael Gitlin, 2004), okay bye-bye (Rebecca Baron, 1998), and spam letter + google image search $=$ video entertainment (Andre Silva, 2005)—figure the archive itself and thus simulate for the viewer the experience of being in an archive, of following and trying to make sense of fragments and traces. More specifically, these documentaries begin by mobilizing material or textual objects to which the filmmaker has some personal connection and follow not the defined trajectory of a journey but, rather, the tentative movements of an exploration. This exploration is often indirect, dispersed, and nonlinear. It foregrounds process, digression, and discovery rather than a straightforward recovery of "the facts." What is most interesting to me, however, is that, in the films I discuss here, the first archival fragment leads to further fragments and, more specifically, to the archive. Part of what is discovered is the archive itself and varying forms of archivization. Thus, each film treats a fragment as a jumping-off point that leads to a relationship with "the real" yet simultaneously interrupts any such unmediated relationship. Each film, in its own particular way, articulates a tension between the figuration of the archive and the use of fragments as well as between the acts of finding things and of making films.

While discourse about documentary has endlessly rehashed the truism that no documentary film is objective despite its implied truth claims, less has been written about the relationship between documentary as a historiographic process and contemporary changes in the wider field of historiographic theory. ${ }^{1}$ Like other forms of historical inquiry, documentary is concerned with questions of how the past may be experienced or understood in the present. Thus, it seems productive to locate documentary practice within this broader historiographic context. Here, I argue that these four contemporary documentaries that figure archives and mobilize archival fragments do so in a way inflected by the methods both of New Historicism in academic historiographic practice and of deconstruction in academic literary and cultural practice. The archive is the common historiographic concept and technology around which these two diverse (and often contradictory) discourses converge. I also suggest, borrowing from historiographer Hayden White, that, in the context of the emergent digital era, the emplotment of the narrative of the archive and hence of the historical project itself in these films is that of satire, accompanied by the partial redemption of comedy and tragedy. Finally, I argue, building on the work of historiographic theorist Eelco Runia, that these films are part of a larger trend in the approach to history, a move away from the "transfer of meaning," or the attempt to narrate and explain history, toward a "transfer of presence," or a sense of contact with the historical past that cannot be reduced to facts and chronologies (17). Indeed, refusing to assert a stable narrative of the past, each of these documentaries offers, rather, an experience of the confrontation with the vast yet always partial and discontinuous archive of materials that precedes any construction of historical understanding.

In my view, what is ultimately at stake in all four films is the relationship between the human subject and the historical past as mediated through different and changing technologies of memory. As material objects are increasingly overwhelmed and outnumbered by digital documents, it has become ever more urgent for us to find new ways of sorting through these traces and to invent new methods for encountering and articulating the past. While many films engage the archive in various ways, these particular films figure the archive in such a way that they dramatize the larger shifts taking place in our cultural and theoretical conception of history. Indeed, they exemplify an emergent strategy within independent documentary film production for dealing with the traces of the past while simultaneously rejecting any simple notion of access to historical meaning, which seems increasingly untenable in the information age. Reflecting this historiographic crisis, they inhabit and thematize the desire for a coherent history confronted by the unruly vestiges of its passage.

\section{Historiography, Deconstruction, Documentary}

Since the 1980s there has been a marked democratization and personalization of historiographic practice at large that has been at least partially spurred by the development of New Historicism. According to preeminent 
scholars Catherine Gallagher and Stephen Greenblatt, New Historicism begins from the premise that there is no single, universal history but rather many histories based in the unique, the particular, and the individual (6). Furthermore, Gallagher and Greenblatt emphasize the way in which New Historicism has opened up the range of topics considered worthy of historical investigation. By conceiving of individual cultures as sets of texts, New Historicists have been able to use almost any aspect of cultural production as a potential historical site for reading and interpretation (Gallagher and Greenblatt 8). New Historicists also acknowledge the fact that any exploration of history is necessarily in part subjective and based in the historian's desire to experience the "touch of the real" (Gallagher and Greenblatt 31).Thus, they often search the archive for eccentric anecdotes and enigmatic fragments in order to construct counterhistories that interrupt the homogenizing force of grand narratives by grounding themselves in the contingent and "the real," all the while acknowledging that the real is never accessible as such (Gallagher and Greenblatt 49). It is the archives and their vast amalgamation of unrelated objects that make the New Historicist project possible. The four documentaries I wish to discuss here are particularly allied with New Historicist strategies in that their self-conscious exploration of the archive and their emphasis on the fragment that disrupts grand narratives bring them into closer alignment than other current documentary forms with the New Historicist project.

Nonetheless, despite commonalities between New Historicism proper and these particular documentary practices, several important distinctions must be made between them. First of all, while New Historicists note the common problems of the excess and inexhaustibility of the cultural archive, they respond in written documents that do not have the same indexical relationship to the historical world as do photographic, filmic, or other audiovisual media, in which issues of excess are even more pronounced. Indexical images as well as sound recordings, quite simply, are even less easy to contain than written documents; their tangibility and ambiguity are often even more unruly. While every trace, written or otherwise, is open to interpretation, indexical audiovisual recordings are especially resistant to full comprehension or interpretation. As Friedrich Kittler has argued, the indexical sign, unlike writing, records all the uncensored, unfiltered "noise," which resists signification (86). Given their unruly excess, audiovisual media often demonstrate (whether intentionally or not) the excess, ambiguity, and disruptive real that are key elements upon which New Historicists base their work. Second, expressed through different media, they differ in their relationships to time and presence. Several of the filmmakers discussed here, in fact, use New Historicist methods not primarily to seek out and disclose the past but rather to explore the present as it is moving into the past, to examine the relationship between past and present, or to seek out traces of the past in the present.

While New Historicism provides one framework for understanding these documentaries, elements of deconstructive practice also emerge forcefully within these works. Deconstructive practice extends from the premise that language and signification are inherently multivalent and that therefore meaning itself can never be stabilized. Its practitioners often interrogate the processes by which texts are made to "mean" something in order to question larger cultural assumptions. Indeed, the use or revelation of the pun or the "play on words" in order to reveal the slippage of the meaning of the signifier is one of the defining tools of deconstructive practice. New Historicists Gallagher and Greenblatt explicitly distance themselves from the critical practice of deconstruction, arguing that it does not take cultural and historical specificity into account (14). I would argue, however, that these documentaries discover and dramatize shared ground between New Historicism and deconstruction. That is, they generate and maintain a productive tension between the description of the specificity of a given cultural and historical situation and an interrogation of textuality itself.

In Dust: The Archive and Cultural History Carolyn Steedman has indicated a way in which rigorous archival research can be combined with deconstructive method. Steedman notes that deconstruction uses the form-not the affect — of the joke, which employs "the calculated naivety involved in the literal interpretation of a trope," thereby "missing the point, in order to make another one" (11). Steedman, in fact, makes use of this joke structure in her book, using Derrida's figurative notion of "archive fever" (mal d'archive) to examine the literal way in which nineteenth-century archives harbored the anthrax virus in the binding of books. Steedman literalizes the metaphor of archive fever in order to begin historicizing bookbinding and industrial diseases, including that of the scholar (28). The joke, which literalizes a metaphoric trope, is thus a form of "misuse" that is also historically productive. In all 
of the documentaries discussed here metaphors associated with the archive are literalized, thereby revealing the slippages in the meaning of the signifier. The literality of these "jokes," however, is grounded in particular in the specificity of the indexical audiovisual trace, thereby mitigating the New Historicist concern that deconstruction is ahistorical and decontextualizing. In sum, the common elements of all these films are, first, the fact that they share a fascination with the archive and archival objects and, second, the fact that they mimic the structure of the joke. This raises the question, What is the affinity between the historical archive and the joke? I would suggest that it has to do with the fundamental ambiguity of the meaning of the archival object as both figurative and literal, which lends itself not only to factual assertion but also to misuse and play.

At this historical moment in particular, when the everexpanding digital archive threatens to overwhelm all narrative coherence, the question of how to organize archival traces and narrate from them any history at all has come to feel increasingly urgent. Hayden White has argued that all historical narratives are emplotted, primarily in the modes of romance, comedy, tragedy, and satire. While the story of the archive itself has often been emplotted in the romantic genre as a recovery and redemption of the past in the form of historical narrative, now the sheer volume of archival materials threatens to undermine the lofty goals of historians descended from Jules Michelet, who dreamed of "raising the dead." Indeed, the romance of the archive now verges on collapse, and the attempt to narrate the experience of engaging the archive seems to have (d)evolved into satire. According to White, "Satire is the precise opposite of this Romantic drama of redemption; it is, in fact, a drama of diremption, a drama dominated by the apprehension that man is ultimately a captive of the world rather than its master, and by the recognition that, in the final analysis, human consciousness and will are always inadequate to the task of overcoming definitively the dark force of death, which is man's unremitting enemy" (9).

I would argue that the structure of the joke as it is mobilized in these films is most closely aligned with satire and its recognition of the inability of any narrative or signification to create a meaningful history in the face of not only the passage of time and of death but also the contemporary proliferation of archival materials. The vacillation between the literal and the metaphoric, and the very glut of signification, renders the presumed meaning of any signification suspect. Indeed, as Freud has pointed out, the uncanny pun signals the death of any absolute meaning ("The Uncanny"). The anxiety about the archive, which is often invoked as a place where the dead are preserved in order to be reanimated by the historian, seems to stem from the fear that the meaning of the traces left by the dead cannot be stabilized. If there is one overarching joke to which all these documentaries subscribe, it may be that, when it comes to history, the joke is on us. No matter how much archival material we may uncover (or perhaps because we have uncovered too much), a coherent history is always just out of reach. Nevertheless, along with the stuff of satire, the joke is also comic, which, according to White, opens up the possibility of some partial redemption (9). Freud, too, notes the association of the joke not only with anxiety but also with freedom, play, and the opportunity to think outside the habitual confines of rational thought (Jokes 10-11). This liberatory potential - the possibility for a playful attitude toward history in the act of writing it-allows these four documentaries to reassert the partial redemption of the comic, as well as the tragic, in the face of a nihilistic view of documentary as nothing but "mockumentary" and of history as pure farce.

\section{The Archive of Noise}

On several levels, Adele Horne's film The Tailenders is structured like a joke, which is not to say that it is overtly comic but rather to point to its productive "misuse" of its materials. To begin with, Horne herself actively misuses the archive of recordings collected by Gospel Recordings and "misses" the intended point of their archive in a subtly critical way in order to show not only its ambiguous nature but also the ambiguous effects of its use on the communities the missionaries target. ${ }^{2}$ In the manner of the New Historicists, Horne uses an odd archival fragment-in the form of the Cardtalk record - to disrupt the grand narrative of Western progress uplifting the non-Western world through religion and technology. ${ }^{3}$ Horne, who never appears on-screen, follows a group of Gospel Recordings missionaries to the Solomon Islands, Baja California, and India to document them carrying out their work. Rather than focusing solely on the missionary organization, however, Horne uses their hand-cranked record player and archive of Bible recordings to explore the experiences of the consumers of the missionaries' wares, the power of the disembodied voice, and the complexities of carrying a particular message across languages and cultures. Without 
ever overtly condemning their project, Horne is able to use Gospel Recordings' archival mission to trace the legacy of colonialism and the flow of evangelism, in concert with the spread of global capitalism and consumerism, into poverty-stricken communities whose traditions and languages are quickly being quashed by all these forces, even as the missionaries attempt to translate "themselves" into the cultures in question. Thus, while telling the history of Gospel Recordings, Horne also tells another history, which is one of exploitation, oppression, and extinction rather than one of uplift and salvation

On this most basic level, the film can be seen as a joke on Gospel Recordings.Yet deconstruction also emphasizes the breakdown of any clear opposition between subject and object, in this case, between the filmmaker and the missionaries, an opposition that Horne herself rejects. Indeed, the film is also concerned with its own textuality as well as with the question of textuality itself. Horne's voice-over, while not the male voice of authority associated with more traditional documentary practice, is, like the sound that emanates from the missionaries' recordings, disembodied. Rather than ignore this "voice of God" transcendence, Horne interrogates the form as she mobilizes it. Without overt wordplay, she literalizes the notion of "Cardtalk," a card that talks, asking what it means for an inorganic object (like a film) to speak with a human voice. Over images of sound recording and playback devices, Horne's disembodied voice asks, "Why are disembodied voices so captivating? . . . Separated from its body, the voice becomes superhuman. It can speak to more people than any single person could. Evangelists began using the disembodied voice in the twenties and thirties." So, too, in the 1930s, one might add, did documentary filmmakers. Thus, without being overtly funny, Horne mobilizes the structure of the joke in order to move from a singular object to much broader questions of power in which her own practice is implicated. She thereby also disrupts the convention of the documentary voice-over that so often, like missionary recordings, speaks with disembodied and transcendental authority.

The Cardtalk record player, which emits the disembodied voice, also directs the film toward the much larger archive of such voices and toward a consideration of the power of archives in general. Horne's film functions, in many ways, as a meditation on the processes of archiving and the collection of the indexical trace, in this instance the audio trace. Like the disembodied voice, archives are about power. As Derrida has pointed out, the archives in ancient Greece were administered by archons, who controlled the gathering and preservation of documents as well as their interpretation and hence their meaning (2). Here, the Gospel Recordings missionaries take on the role of the archons, choosing what is to be collected. Without overtly judging the collection of recordings, The Tailenders produces a sense of ambivalence about the missionaries' archive, which contains recordings of over five thousand languages and dialects, many of which are no longer spoken or are soon to be lost. Clearly, there is an allure to this archive of dead or disappearing languages, but there is also a clear sense of the archive's selectivity, the fact that whoever decides what to archive also controls what traces will be available in the future. On the one hand, these are valuable indexical traces of certain languages that are gone or soon to be gone. Indeed, it is difficult not to admire an organization that has been able to amass recordings in so many languages and dialects. On the other hand, this admiration is accompanied by the realization that these recordings are only of Christian Bible stories: what is saved is determined by the missionaries, who have the privilege of deciding what counts.

Yet (and this is part of the joke, too), the film also points to the fact that archives and the indexical traces they preserve often escape the control of the archons. These traces mean more than the archons might intend or wish. Film theorist Mary Ann Doane, following Kittler, has suggested that the ability of technologies of mechanical reproduction to create indexical traces holds both the allure of the preservation of the past and the threat of preserving too much, of generating only an "archive of noise" (65). New Historicists Gallagher and Greenblatt emphasize the seductive lure of the archive as the place where one may encounter "the touch of the real" and the "luminous detail" (15), but, at the same time, they acknowledge the potential problem of counterhistory as a practice, in which anything may constitute a trace of the real (72). Horne's film expresses a similar experience of allure and threat, but it also, simultaneously, thematizes and literalizes this notion of the "archive of noise." For one thing, the missionaries' recordings themselves go beyond the control of meaning as intended by the missionaries. Most fundamentally, the film illustrates the problem of the subtle transformations of meaning inherent even in an "accurate" translation from one language to another. Furthermore, in one interview a Gospel Recordings member discusses some of the additional problems of making recordings in 
languages that the missionaries themselves do not understand. Sometimes, he explains, the translators themselves "misuse" the recording process, making mistakes and taking liberties with the biblical stories, as in the example of one translator who turned the story of the prodigal son into the story of the prodigal pig. The intended biblical meaning is transformed into "nonsense." Even more crucial to the "archive of noise" in the film, however, are the literal noises on these missionary soundtracks. Missionary interviews and written archives attest to the fact that local conditions often do not allow for a clean, crisp recording. Crickets, domestic animals, children playing, and other noises are captured on the recording and cannot be eliminated. The "thickness" of the indexical sound recording produces an unintended encounter with and description of "the real" and thus generates the threat - for the missionaries - of losing control of meaning, of excess and inexhaustibility. However, rather than seeing noise as threat, The Tailenders celebrates the liberatory effect of "noise" as the breakdown of the missionaries' control. For Horne, the problems encountered by Gospel Recordings point to the fact that local realities cannot be fully contained or silenced by the voice of Western missionaries and the global marketplace. An archive of instrumental power is subverted, (mis)used for different ends - or for no end at all, for play. While, on the one hand, the film satirically narrates the archive as an instrument of social control rather than of truth, it also reasserts the comedy of the archive as a site of liberation from these very sources of control through misuse and play.

Appropriately, the film itself rejects the role of the archon, refusing to offer a definitive account of the historical significance of its own materials. Like the New Historicists, Horne uses her objects and anecdotes not to construct a grand narrative but to throw such narratives off track without establishing any other unitary meaning. The film offers potential insights into the archival process and its consequences, and yet, by withholding explicit judgment, it hovers on the edge of itself becoming "noise." It works to provoke and evoke rather than to judge or explain. In the end, although we know much more about it, the disembodied voice emanating from the Cardtalk record player remains a subtly disturbing enigma.

\section{The Archive as Taxonomy and Taxidermy}

The uncanny encounter with an archive of bodiless voices in The Tailenders finds an echo in Michael Gitlin's film The
Birdpeople, in which the taxidermic body of the (most likely) extinct ivory-billed woodpecker is the ambiguous and opaque object that structures the film. The New Historicists suggest that archival fragments are alluring because of their radical alterity and their ability to puncture historical platitudes. The taxidermic body suggests just such radical alterity. It also exists in a special relation to time. As Steedman writes, "In the practice of History (in academic history and in history as a component of everyday imaginings) something has happened to time: it has been slowed down, and compressed. When the work of Memory is done, it is with the things into which this time has been pressed" (79). In Horne's film time has literally been "pressed" into the Cardtalk record in a record press. In Gitlin's film the stuffed body of the ivory-billed woodpecker becomes the technology of memory into which time has been pressed. Nonetheless, it would be misleading to say that the film is about the ivory-billed woodpecker. Like Horne's “misuse" of Gospel Recordings' recordings and archives, Gitlin's film is also structured as a joke. Gitlin uses the stuffed, dead body of the ivory-billed woodpecker and the marginal practices of bird-watching, bird banding, and avian taxidermy to address larger questions about the impulse to observe, preserve, catalog, and archive by turning his subjects' strategies of archivization back on themselves - and by reflecting on film as an archival medium itself.

As in New Historicism, in which idiosyncratic fragments are used to illuminate historical norms, marginal practices of archivization in the film serve to underscore the normative status of the urge to collect experiences, data, and objects. The Birdpeople provides a catalog of different kinds of avian archives, their justifications and their production of "evidence," which become part of larger archives of knowledge or experience. Each type of activity represented in the film serves as an instance of a particular technology of memory available at a given cultural moment. The film, in fact, creates an overt taxonomy of these mnemonic technologies and the "birdpeople" ("birders," "banders," "scientists," and "searchers") who put these technologies into practice. Himself an amateur birder, Gitlin does not so much make fun of the people who obsessively collect sightings of birds as ponder their impulse to look and then to catalog these looks in written or unwritten transcripts. Birders thus produce an archive of what they have seen without necessarily preserving an image or any other indexical form of representation. Their 
prosthetic tool is the binoculars rather than the camera, and their archives exist mostly in individual memories or on slips of paper inscribed with name, date, and location. Meanwhile, catching live birds in nets, the banders document the numbers of bird species present in an area and take measurements of these live birds before tagging and setting them free, thereby producing extensive facts and figures about bird populations even as this "living archive" of tagged bird bodies wings its way through the trees. This is not to say that nature itself is an archive but rather that the banders attempt to impose an order on nature through their taxonomic activities. While the banders seek to control the excess of nature in the present, the avian taxidermists attempt to impose a similar order onto nature in the past tense, preserving the bodies of dead birds as museum exhibits or tools for future research. For the searchers, people who spend months in the swamps looking for a visual or audio trace of the vanished ivorybilled woodpecker, the living body of this bird is figured as a redemptive icon of the past in its ultimate sense: extinction. These searchers do not produce an archive but, rather, like the historian in the archive, attempt to do no less than raise the dead. In doing so, they point to what is missing in the archives produced by the birders, banders, and taxidermists, to the absences that are an inherent part of every archive.
The archive as a raising of the dying, the dead, and the extinct is perhaps the underlying logic of all of these practices. At the same time, however, there is a sense that the archive is beyond the control of any of the individuals within the film. The birders may have the most control over their archive, for they are the only ones who can access it, but their archive of personal encounters is limited in that it cannot be used by anyone else. By contrast, the banders' data become part of a larger instrumental archive within which the banders themselves have almost no control. Similarly, one taxidermist says, "Twenty years down the road, people may be thinking about things we can't even envision right now, and these specimens that I laid down two decades ago will be really important." Although the taxidermist speaks in a utopian tone, his comment also serves to underscore the fact that his work - his archival data-could be used for almost any purpose in the future. Meanwhile, the searchers produce only a failed archive of false sightings and recordings, and their motivation for seeking evidence of the extinct woodpecker's continued existence is entirely unclear. It seems like pure obsession and, to a great degree, undermines all of the justifications all of the birdpeople make in the film for their actions. The impulse to create an archive, to produce evidence of "having been there," of "having seen," to assert control by stalling or turning back death, is more powerful than any rational motive.
Figure 2. The taxidermic body of the ivory-billed woodpecker in The Birdpeople (Michael Gitlin, 2004).

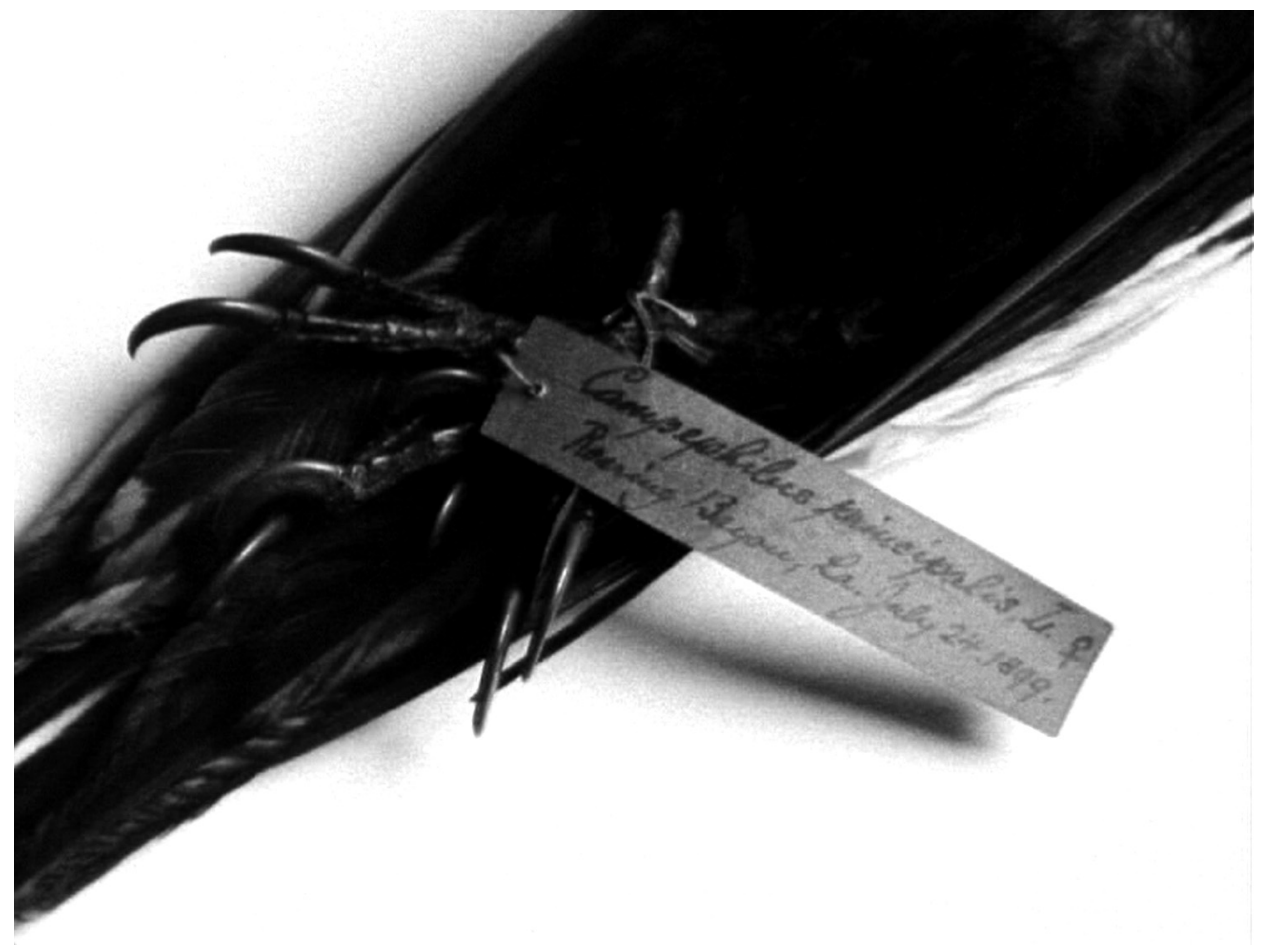


Like Horne, Gitlin recognizes his own complicity in archivization. The impulse to make films, Gitlin subtly implies, especially the urge to make documentaries, may be the result of the same obsession. André Bazin's description of cinema as a result of the historical obsession with likeness and as a preservation against death, which he calls the "mummy complex" (9), already points to the connection between filmmaking and taxidermy. Fatimah Tobing Rony extends this comparison in her discussion of the "ethnographic taxidermy" practiced by documentary filmmakers like Robert Flaherty, who tried to make a dead indigenous culture look alive for white consumption (99-126). Filmmaking itself is a technology of history and memory and thus emerges from an archival impulse to record and save. Indeed, because Gitlin's film is structured as a taxonomy rather than a narrative, it echoes the nonnarrative, categorical structure of an archive. Moreover, the taxonomic structure and the formal parallels drawn between human bodies and animal bodies produce a blurring of the boundaries between animals and humans, nature documentary and ethnographic film, taxidermy and filmmaking.

Indeed, purporting to be about people who watch, band, stuff, and search for birds, The Birdpeople, in fact, turns the birdpeople's own archival strategies back on themselves. For one thing, the film is as much about watching people as it is about watching birds. While Gitlin's film simulates the act of bird-watching through binoculars, it also performs an ethnographic inspection. As he documents the processes of avian archiving, Gitlin also films the birders themselves, revealing the voyeuristic aspect of birding. As he points out, the birds look back at the camera or the binoculars, but theirs is an ambiguous gaze, although not the threatening or threatened returned gaze of the ethnographic subject. The bird is a "safe" other whose gaze does not matter. Gitlin's camera, however, is another matter. When he frames the birdpeople individually, standing silent and almost motionless in long takes, he seems to be literally producing "ethnographic taxidermy" in the form of images. In most cases the birdpeople's discomfort at being looked at and recorded is palpable. Although compelled by the archival impulse, most of the birdpeople seem much less comfortable being themselves preserved in the archival medium of cinema.

This discomfort comes as no surprise, since the verbal discourse produced by all of the birdpeople in the film reveals the theme of death, extinction, and loss implicit in all archival practices. In fact, the birdpeople perform a displacement of the discourse of "salvage ethnography" from the ethnographic subject to the animal subject, anthropomorphizing the bird, who, like the Native American "noble savage" in colonial discourse, is posited as always already disappearing (Rony 91).Thus, the gaze of the birder is revealed as a colonizing gaze, while the gaze of Gitlin's camera is precisely a taxidermic gaze, since the images will presumably outlast the individuals that Gitlin films. Indeed, The Birdpeople moves from an archive of dead bird bodies to a taxonomy and taxidermy of living human bodies, creating an uncanny parallel between looker and lookedat, mummified and photographed, and producing the sort of laughter that is edged with anxiety and the thought of death.

\section{The Unintended Reader}

Like The Tailenders and The Birdpeople, Rebecca Baron's film okay bye-bye both represents and interrogates archival forms. It takes an epistolary form, a cinematic letter addressed to an unspecified "you" from a quasi-autobiographical "I" narrated by the filmmaker. Here again the structure of the joke appears as a literalization of the metaphor of the archive. The epistolary format is, of course, one of the most common forms of archival document. Indeed, along with the official record and the photograph, the letter may be the archival document par excellence. Steedman points out, however, that, like the reader of a letter sent to someone else, the historian who uncovers any object in the archive will always, in some sense, steal or misuse it: "The Historian who goes to the Archive must always be an unintended reader, will always read that which was never intended for his or her eyes. Like Michelet in the 1820s, the Historian always reads the fragmented traces of something else ... an intended, purloined letter" (75). The act of viewing a documentary film is always in some way an act of "reading" a purloined letter. However, okay byebye literalizes this situation by actually placing the viewer in the position of the historian in the archive, reading letters addressed to someone else. That is, we never find out exactly who the narrational "I" is or to whom she is writing, but we remain intensely aware that we are reading someone else's letter.

Although the film text does not begin with a fragment, a fragment of film both was the actual instigation of the film and becomes the impetus for the narrator's search to 
understand its meaning in relation to herself. In a few silent seconds of a Super-8 film fragment a Cambodian man gestures and talks, as if telling an exciting story. The filmmaker/narrator - who are not entirely coincident - found this piece of film, labeled with the name of a Cambodian city, on a sidewalk in San Diego, California, and it serves as a starting point for (among other things) an investigation of the Cambodia genocide under Pol Pot, the role of the United States in Cambodia during the Vietnam War, and the Cambodian immigrant population in Southern California.The film makes use of a variety of archival materials: microfiche copies of the New York Times, old ethnographic and military footage, and - most strikingly - the online databases of photographs of the victims of the Cambodian genocide, taken, in fact, by Pol Pot's Khmer Rouge in the S-21 camp right before the prisoners were shot and killed. All of these archival materials are presented as actively found by the filmmaker/narrator, not as simply given. In fact, the film is very much about the personal process through which these further fragments were discovered and about their promise of a coherence that ultimately cannot be realized. While all of the films discussed here are about how the past - or elements of it - is preserved in one form or another, this film is the most explicitly about memory and how technologies of archiving affect what and how a culture remembers as well as what and how it forgets. Baron's film not only enacts the desire to turn archival fragments into a narrative but also suggests that certain fragments can never be contained by a story. Indeed, the film fragment that sets off the narrative is ultimately unassimilable to narrative; its meaning is left open and unresolved.

While the epistolary format puts the film viewer in the position of an unintended reader, the narrator is explicitly aware that she herself is reading a set of "letters" that are not addressed to her. The S-21 archive is perhaps the most distressing of these, for its contents were "written" by the Khmer Rouge, who took pictures of their victims moments before their deaths. To whom could these images have been addressed? For what purpose were they intended? Is this some grisly historical joke? The Khmer Rouge photographers surely could not have imagined the contexts into which the images they made would be put: a museum exhibit, a coffee-table book, an online database, or an experimental documentary film. These "letters," "sent" by the Khmer Rouge (perhaps to themselves), have been archived, appropriated, and "misused."

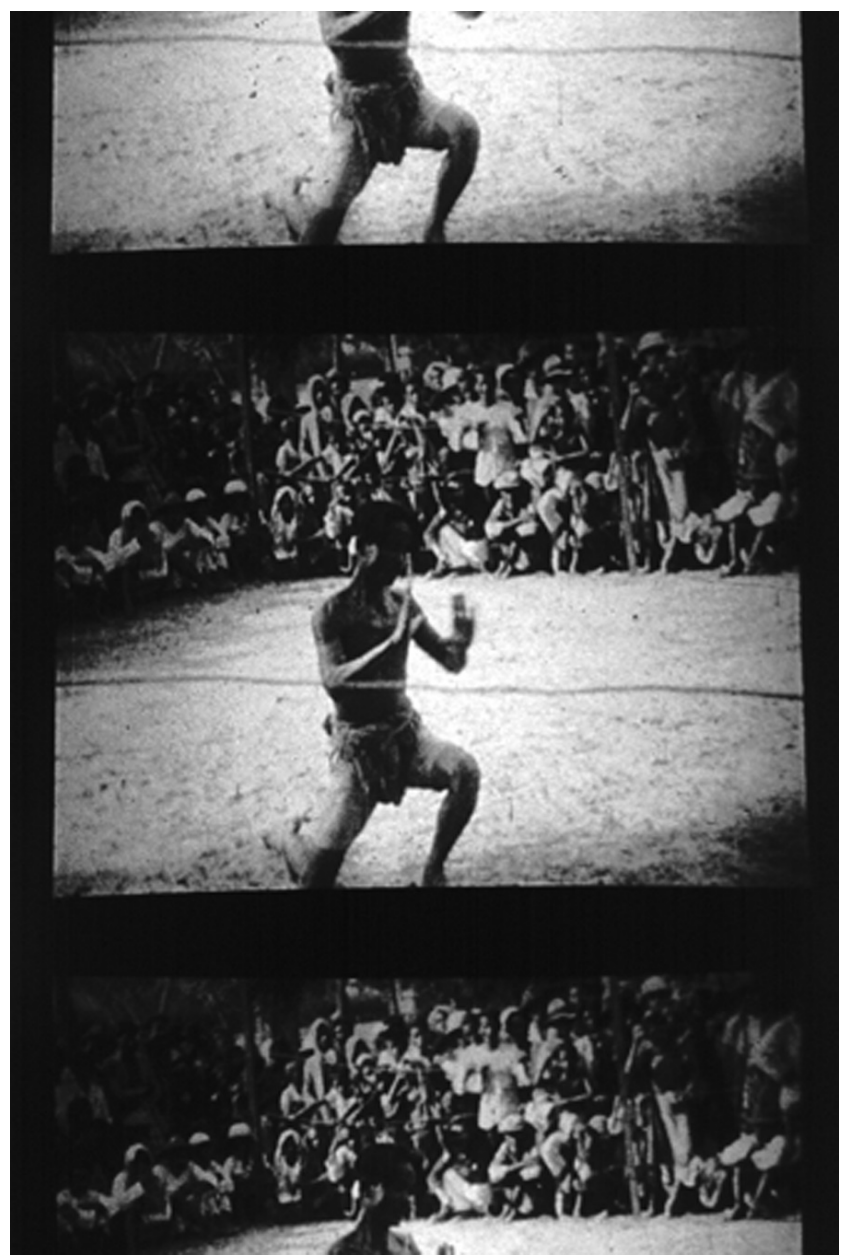

Figure 3. A strip of found archival film showing a boxer in okay bye-bye (Rebecca Baron, 1998).

Thus, like The Tailenders and The Birdpeople, Baron's film raises the question of how archival materials circulate and how they are made to speak according to circumstances that long postdate their production. The narrator of okay bye-bye realizes that she is responding to the images in terms of their strange beauty and uncanny attraction, the people's hair and men's beards, the lighting of the shots. Certain thoughts, it seems, are inappropriate to the objects, and yet there is no denying the aesthetic allure of these death masks, now archived online. Here, the fact of the digital archive in particular raises questions about the leveling of images and their meanings. The dystopian nightmare of the digital age involves the way in which the Internet, the archive, and perhaps any technology of memory are both selective and valueless. What finds its way into the digital archive depends on who finds what images and chooses to make them available. Even 
more frighteningly, all images on the Internet have the potential for a problematic equivalence, for becoming just another combination of ones and zeroes that may generate moments of enlightenment but that may also generate meaninglessness. At the same time, the utopian dream of the Internet is that of access, communication, and connection, through which relatives of the S-21 victims may recover their dead. While the first view coincides with the satirical recognition of archival meaninglessness, the second offers some hope for the redemption of meaning, although emplotted more in the mode of tragedy than comedy.White writes: "The reconciliations that occur at the end of Tragedy are much more somber [than those in Comedy]; they are more in the nature of resignations of men to the conditions under which they must labor in the world. These conditions, in turn, are asserted to be inalterable and eternal, and the implication is that man cannot change them but must work within them" (9).

okay bye-bye may be read as both satire and tragedy in its emplotment of the story of the archive. The found fragment of film (a piece of detritus on the street), the epistolary missives of the narrator, and the many archival documents shown neither cohere as a unified narrative nor establish a definitive meaning. Instead, the film acts as a succession of encounters and interruptions that are only tentatively held together by a delicate narrative thread of reflexive meditations. Nonetheless, the film asserts the need to continue to sort through archival traces even if they will never yield any definitive conclusions.

\section{The Archive as Spam}

While films categorized as "found footage films" often engage with the archive in various ways, okay bye-bye may be better classified as a "finding footage" film, in which the found fragment provides only a starting point for the documentary filmmaker's confrontation with and attempt to convey some aspect of the historian's impossible task. Indeed, the film discovers not only a fragment but also the vast archives that give the fragment the promise- unfulfilled, because it cannot be fulfilled-of meaning. The same is true of a very different film, which begins not from a piece of film but rather from a spam letter. Andre Silva's spam letter + google image search $=$ video entertainment seems - at least at first glance - in line with what William Wees has called the "appropriation film," a postmodern form of found footage film that, instead of "quoting history" like the "compilation film," "quotes the media, which have replaced history and virtually abolished historicity" (45). I would argue, however, that rather than being abolished by Silva's film, historicity, by its absence, is precisely its topic. While this film is more likely to be classified as an experimental film than as a documentary, I wish to make the argument that it is indeed a documentary, precisely because it illustrates and simulates the relationship between the contemporary reader and the digital archive and because all of its constituent parts are found rather than invented by the filmmaker. Moreover, its use of the archive is so disturbing to conventional notions of history that, I contend, the film is forced to change genres, ousted from the realm of documentary to be classified and contained in the category of the experimental. Looking at it as a documentary, however, challenges the distinction between "proper" and "improper" uses of the archive as well as reified notions of the historical.

As in okay bye-bye, issues of the letter to the unintended reader and of the endless digital archive are also taken up by Silva's three-minute film. Silva, like many of us, was the recipient of a generic spam letter sent to thousands of users ostensibly from a lawyer in Nigeria asserting that, because the addressee bears the same last name as his deceased client, the addressee is the client's next of kin, and thus, with the addressee's help, the client's money can be repatriated to the United States, whereupon the lawyer and the addressee can split the profits. Silva took the letter and performed a Google image search of each word in the letter. He then programmed the letter into the computer's voice generator. In the film, as each word of the letter is spoken by the computer, it is accompanied by the first Google image that came up for each word. The result is a bizarre sequence of images that bear heterogeneous and often incomprehensible relationships to the words they "represent." Every element of the film is drawn from (virtual) objects that, like the letter itself, circulate in the vast, active archive of the web. The spam letter acts as the fragment that leads to this greater archive.

In this case, the fragment is literally a spam letter received by an unintended reader. The name of the dead man, whose last name Silva is supposed to share, is actually not "Silva." Moreover, spam letters and most web pages, like films and other technologies of memory, are epistles sent into cyberspace that can be read by anyone and interpreted by anyone who happens to receive the message. In this perverse form of epistolary documentary, the letter 
is meant to be read-by anyone with a checkbook. On the one hand, the Internet's field of messages presents a utopian vision of the active, agentic reader who has access to all material. And yet again, on the other hand, we once again encounter an "archive of noise," of meaninglessness or nonsense, of letters not intended for us in particular or perhaps for anyone in particular.The film is a Frankenstein patchwork of voices and images, the digital archive talking to itself about everything and nothing. If there is anything at all that controls what is meaningful here, it is the search engines, inhuman technologies of memory (or the navigation of memories) without affect or intentionality. How can one think of history here? And yet, precisely because history is so thoroughly devastated by the film, the question of - even the demand for-historicity returns in all of its insistence.

Of all of these films structured like a joke, spam letter is both the most satirical and unambiguously funny. The most humorous moments are those when a word is used aurally in one manner but is accompanied by an image that is associated with another-and often literal-meaning of the same word. For instance, the possessive pronoun "mine," used in the voice-over to mean "belonging to me," is accompanied by an image of a miner's lamp. Other combinations require other kinds of leaps of (il)logic, for Google image search, of course, is not based on contextual thought. The resultant humor is informed by the threat of the archive (specifically, the digital archive of the Internet): that even uncanny double meaning will be overwhelmed by meaninglessness. As in all of the films discussed above, the death of meaning is closely associated in this film with death itself: the dead client in the spam letter, images of death offered by the search engine, and "dead" web pages, no longer meant for anyone. Death always seems to accompany the archive. At the same time, however, the film is terribly funny and enjoyable, which suggests that comedy reasserts itself even within this nihilistic satire. Perhaps, the film suggests, in the face of the satire of history, the only possible response is to laugh and go on seeking the past through its traces, in all of their terrible excess.

\section{The Fragment as Metonym}

Ultimately, all of these films can be read as both enacting and representing the impulse to create archives while simultaneously engaging the viewer in the historian's experience of confronting the excess of the archive. Fur- thermore, since textuality and signification are constantly in question in these films, none of the films purports to be comprehensive or fully coherent, closing the book, as it were, on the meaning of its subject. Indeed, the fragment that structures each film does not act so much as a metaphor as a metonym. Runia argues that today the key historical trope is not metaphor but metonymy. He writes, "Metonymy may be described as the willfully inappropriate transposition of a word that belongs to context 1 . . . to context 2[,] . . . where it subsequently stands out as just slightly "out of place"” (15-16). For Runia, unlike the metaphor, which is concerned with a "transfer of meaning," the metonym is concerned with a "transfer of presence," that is, a transfer of experience and affect generated by the uncanny contrast between words, objects, and contexts that are incommensurable with one another (17). In this sense, the metonym has much in common with the literalizing joke, which, in literalizing a metaphor, rejects the metaphoric and its promise of a corresponding meaning. Each archival fragment in these films can be seen as a metonym, for it does not so much make meaning as offer a point of entry - through something out of place - to an experience of the uncanny. Metonymy, unlike metaphor, refuses to reduce or comprehend meaning. "Whereas metaphor 'gives' meaning, metonymy insinuates that there is an urgent need for meaning. Metaphor ... weaves interrelations and makes 'places' habitable. Metonymy, on the other hand, disturbs places" (19). The refusal of these documentaries to come to any conclusive interpretations can thus be seen as a function of the disruptive, metonymic role of the fragment. Although potential meanings emerge in each film, the most powerful effect of each film is a sense of the disturbing and overwhelming presence of the cultural archive, with its seemingly infinite and yet always partial store of images, sounds, and objects. Against the alreadyaccepted yet unstable norms of the information age, these films question the nature of "data" and "information": what they consist of, who determines access to them, and to what multifarious uses they can be put. It is, then, the metonym rather than the metaphor that offers the comic or tragic release from the satire of meaning(lessness) in the form of a transfer of the presence of history, rather than its meaning, to the viewer. The joke, the fragment, and the metonym in these films all hold the potential for epiphany or at least the revelation of this disorienting contemporary situation.

The stake of these films is the ability of our society in general, and documentary film in particular, to engage in 
this present moment with the past, with the dead and what they have left behind. All four films confront the question of death that haunts each of the fragments - dead languages, dying cultures, dead species, victims of genocide, dead clients, dead letters, and dead web pages - as well as the need for new ways to sort through their traces, through all that does not go away. Steedman argues that the logic of "dust" is precisely the logic of the indestructibility of matter (164). Matter may be transformed but never destroyed. At this historical juncture, material traces of all kinds are being transformed by digital media. As Derrida has pointed out, new technologies of memory may alter our conception of the psychic apparatus and, by way of these new technologies, transform human memory itself (16-17). One question raised by all of these documentaries is what exactly will survive this particular transformation.

New Historicists have recognized the threat of the excess of material in the cultural archive that has expanded to include almost any cultural object. The deconstructive mobilization of the literalizing structure of the joke offers one way in which to deal with the paradoxical situation of the overwhelming accumulation and presence of information accompanied by the irreversible loss of people and animals that have left only a limited field of traces. Following fragments and "misusing" them as metonyms that offer both a satire of meaning and a redemptive "transfer of presence" is thus one strategy for navigating the excess and impermanence of the information age in which only what is digitized matters but in which it is hard to distinguish between meaningful evidence and meaningless spam. These four documentaries, combining the techniques of New Historicism and deconstruction, use the fragment as an occasion to obliquely address these larger questions of how we can deal with textual production that has already gone far beyond any individual's - and even perhaps any state's or organization's-control.The liberatory effects of this transition cannot be separated from the anxiety that this loss of control entails.

\section{Notes}

1. For a broader theorization of the relationships between documentary, historiography, and indexicality see Rosen (225-63).

2.The missionaries call their potential converts "tailenders" because the missionaries believe that these people are the last on earth to learn about the Christian faith and therefore to be "saved."

3. Although she never says so in the film, in an interview Horne has said that she has a personal connection to this kind of record player because her family had one when she was a child.

\section{Works Cited}

Bazin, André. What Is Cinema? Volume 1. Trans. Hugh Gray. Berkeley: U of California P, 1967.

Bruzzi, Stella. New Documentary: A Critical Introduction. London: Routledge, 2000.

Derrida, Jacques. Archive Fever: A Freudian Impression. Trans. Eric Prenowitz. Chicago: U of Chicago P, 1995.

Doane, Mary Ann. The Emergence of Cinematic Time: Modernity, Contingency, the Archive. Cambridge: Harvard UP, 2002.

Freud, Sigmund. "The Uncanny." The Standard Edition of the Complete Psychological Works of Sigmund Freud.Vol. 17. Ed. and trans. James Strachey. London: Hogarth, 1953. 219-52.

. Jokes and Their Relation to the Unconscious. Trans. James Strachey. New York: Norton, 1960.

Gallagher, Catherine, and Stephen Greenblatt. Practicing New Historicism. Chicago: U of Chicago P, 2000.

Kittler, Friedrich. Gramophone, Film, Typewriter. Trans. Geoffrey Winthrop-Young and Michael Wutz. Stanford: Stanford UP, 1986.

Rony, Fatimah Tobing. The Third Eye: Race, Cinema, and Ethnographic Spectacle. Durham: Duke UP, 1996.

Rosen, Philip. Change Mummified: Cinema, Historicity, Theory. Minneapolis: U of Minnesota P, 2001.

Runia, Eelco. "Presence." History and Theory 45.1 (2006): 1-29.

Steedman, Carolyn. Dust:The Archive and Cultural History. New Brunswick: Rutgers UP, 2002.

Wees, William. Recycled Images: The Art and Politics of Found Footage Films. New York: Anthology Film Archives, 1993.

White, Hayden. Metahistory: The Historical Imagination in NineteenthCentury Europe. Baltimore: Johns Hopkins UP, 1973. 